\title{
Random pharmacokinetic profiles of EC-MPS in children with autoimmune disease
}

\author{
Guido Filler*, Ajay Parkash Sharma, Deborah M Levy, Abeer Yasin
}

\begin{abstract}
Background: Therapy with mycophenolate mofetil (MMF) has become a valuable therapeutic option in children with autoimmune disease. MMF prescription in children with autoimmune diseases differs from that in transplant recipients in terms of different dosing regimen, and concomitant administration of other immunosuppressive medications. Recently, another formulation of the same active compound, mycophenolic acid (MPA), has become available as enteric-coated Mycophenolate Sodium (EC-MPS). Dosing and pharmacokinetics of EC-MPS in pediatric autoimmune disease have never been studied.
\end{abstract}

Methods: We therefore performed a pilot study on 6 patients, who were treated with EC-MPS. All patients underwent 1-2 full 10-point pharmacokinetic (PK) profiles over a 12-hour dosing interval. We compared the results with that of 22 similar patients on MMF therapy.

Results: Median EC-MPS dose was $724 \mathrm{mg} / \mathrm{m}^{2}$ (range $179-933 \mathrm{mg} / \mathrm{m}^{2}$ ). The MPA Area-Under-The-(TimeConcentration)-Curves (AUCs) on MMF and EC-MPS were comparable (54.4 mg $\times \mathrm{h} / \mathrm{L}$ on MMF and $44.0 \mathrm{mg} \times \mathrm{h} / \mathrm{L}$ on EC-MPS, n.s., Mann Whitney). After correcting for bioequivalence, the dose-normalized AUCs were also similar on both the formulations. However, PK profiles on EC-MPS were quite random, and time to maximum concentration varied from 30 minutes to 720 minutes. The concentration at six-hour correlated best with the AUC. This was different from a homogenous PK-profile on MPA.

Conclusions: EC-MPS has a different PK profile from MMF. The data suggest that patients on EC-MPS must undergo a complete PK profile to assess adequate exposure. The 6-hour concentration provides an estimate of the exposure and should be targeted between $3-4 \mathrm{mg} / \mathrm{L}$.

\section{Background}

Mycophenolate mofetil (MMF) is an immunosuppressive drug that reversibly inhibits the inosin monophosphate dehydrogenase (IMPDH), thereby providing selective inhibition of the proliferation of $\mathrm{B}$ and T-cells as they require de-novo synthesis of purines [1]. MMF has become a valuable treatment option for adults and children with autoimmune diseases. A recent randomized controlled clinical trial suggests equal efficacy when compared to cyclophosphamide for the initial treatment of lupus nephritis [2]. There are few publications on the dosing of MMF. Based on pharmacokinetic studies in children with autoimmune disease, an initial dosing of MMF at $900 \mathrm{mg} / \mathrm{m}^{2}$ in two divided doses is recommended [3]. This dose is lower than that recommended

\footnotetext{
* Correspondence: guido.filler@lhsc.on.ca

Department of Pediatrics, University of Western Ontario, Ontario, Canada
}

for pediatric renal transplant recipients, where the starting dose should be between 1200 and $2400 \mathrm{mg} / \mathrm{m}^{2}$, depending on the concomitant calcineurin inhibitor. The reasons for different dosing of MMF in pediatric rheumatology patients as compared to pediatric renal transplant patients is explained by the lack of a concomitant calcineurin inhibitor. There are drug-drug interactions between both calcineurin inhibitors and MMF that explain the variable dosing requirements [4].

The AUCs obtained with the pediatric MMF dose of $900 \mathrm{mg} / \mathrm{m}^{2}$ in pediatric lupus patients compare favorably or slightly higher than those in adults on a dose of $1 \mathrm{~g}$ PO twice daily [5]. Therapeutic drug monitoring (TDM) of MMF therapy is recommended in patients with autoimmune disease and typically done by trough level monitoring because of high inter-individual variability and unpredictable MPA exposure with a fixed MMF dose while there is a concentration-effect 
relationship between the MPA trough level and immunological disease activity parameters [6].

Recently, a novel formulation of the active compound, mycophenolic acid (MPA), was introduced as entericcoated mycophenolate sodium (EC-MPS). It was hoped that this compound reduced the frequent gastrointestinal side effects of MMF [7]. In the province of Ontario, the government no longer reimburses MMF for patients with autoimmune disease, thereby forcing physicians to prescribe EC-MPS instead. While the literature suggests that the pharmacokinetics are radically different in transplant recipients (reviewed in 5), studies on the pharmacokinetics of EC-MPS in children with autoimmune disease remain elusive. We compared the results of 5 patients with EC-MPS with historical PK profiles from 22 patients who received MMF therapy.

\section{Methods \\ Patients}

The previous study [3] that established the dosing of MMF in pediatric rheumatological patients was approved by the hospital Research Ethics Committee. As only six patients were on EC-MPS, and as pharmacokinetic monitoring of MMF and EC-MPS therapy is clinical routine in our unit, we did not seek ethics approval for the analysis of the PK profiles from these six patients. Of these six patients, three had Systemic Lupus Erythematosus (SLE), one had sarcoidosis and two had an autoimmune glomerulonephritis.

The control group with MMF therapy has been described earlier [3]. In addition to the 15 patients that were published, 7 additional patients with SLE were included. All underwent standard immunosuppressive treatment prior to MMF initiation. MMF $\left(\right.$ Cellcept $\left.^{\circ}\right)$ was obtained from Roche Laboratories, Nutley, NJ, USA. Only 250 and $500 \mathrm{mg}$ capsules were used. The patients on EC-MPS were treated with Myfortic $^{\circ}$ obtained from Novartis Canada, Mississauga, ON, Canada, and 180 and $360 \mathrm{mg}$ capsules were used.

\section{Methods}

Standard laboratory test results were retrieved from the patient's files. All patients (on MMF or EC-MPS) underwent therapeutic MPA monitoring using trough levels with a commercially available automated EMIT assay [8]. After establishment of stable trough concentrations between 1 and $5 \mathrm{mg} / \mathrm{L}$, all patients had at least one full pharmacokinetic (PK) profile. PK profiles were obtained after inserting an intravenous cannula and obtaining a baseline trough level $(\mathrm{C} 0)$ in a fasting state usually early morning. The patients then took their usual dose of MMF or EC-MPS and immediately thereafter ate a standard meal. They had free access to non-dairy product drinks during the day and regular meals. EDTA whole blood samples $(2 \mathrm{~mL})$ were then taken for duplicate measurements of MPA concentration at $0.5,1,1.5,2,3$, 4, 6, 8 and 12 hours, respectively for a 10 point 12 hour PK profile. The area under the curve was calculated according to the trapezoid rule.

\section{Statistics}

All contiguous data were tested for normal distribution using the Kolmogorov Smirnov test. In case of normally distributed data, results were presented as mean \pm standard deviation (SD), whereas non-normally distributed data were expressed as median and $25^{\text {th }}$ and $75^{\text {th }}$ percentile. Standard correlation analysis was performed using appropriate parametric or non-parametric approaches. Comparisons between groups were performed using t-test for normally distributed data and Mann-Whitney test otherwise. A p value of less than 0.05 was considered significant. All statistical analysis was performed using GraphPad Software for Science Version 4.01, San Diego, CA.

\section{Results}

All variables under study were investigated for normality using the Kolmogorov Smirnov normality test and most variables were found to be not normally distributed. For consistency, all statistical measures of parameters were, therefore, reported as median, $25^{\text {th }}$ and $75^{\text {th }}$ percentile. The analysis of the PK profiles of the 22 patients with pediatric autoimmune disease is given in figure 1. Following oral administration, the drug is rapidly absorbed (median $\mathrm{t}_{\max } 60$ minutes, a second peak at 6 hours, figure 1).

By contrast, $\mathrm{t}_{\max }$ was later on EC-MPS with a median of 180.0 minutes $\left(25^{\text {th }}\right.$ percentile 60 minutes, $75^{\text {th }}$ percentile 240 minutes, range 30 to 720 minutes). Median $\mathrm{C}_{\max }$ was $20.1 \mathrm{mg} / \mathrm{L}\left(25^{\text {th }}\right.$ percentile $10.3,75^{\text {th }}$ percentile 45.1). The median pre-dose trough level $\mathrm{C} 0$ was 2.76 $\mathrm{mg} / \mathrm{L}\left(25^{\text {th }}\right.$ percentile $2.29,75^{\text {th }}$ percentile 5.55$)$. The median dose per $\mathrm{m}^{2}$ body surface area had a median of $724.2 \mathrm{mg} / \mathrm{m}^{2}\left(25^{\text {th }}\right.$ percentile $660.2,75^{\text {th }}$ percentile

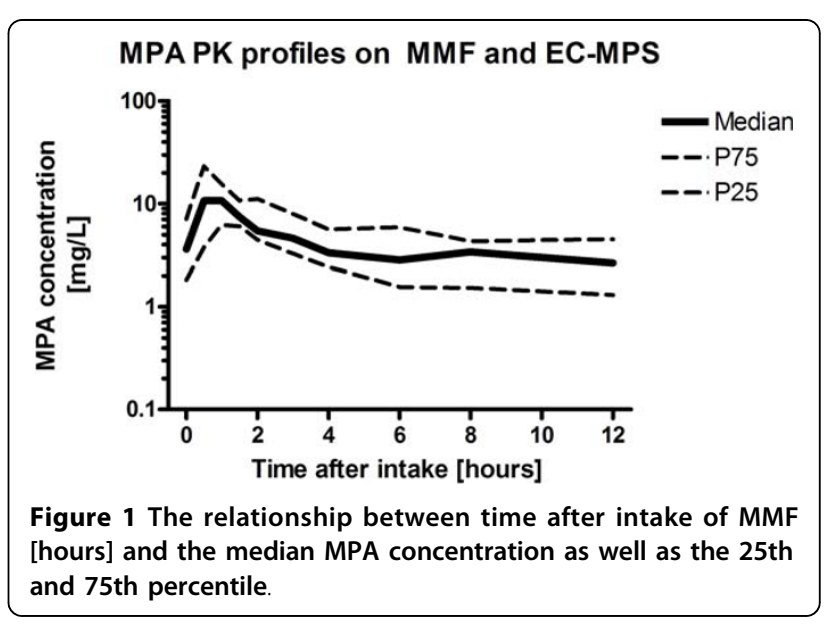




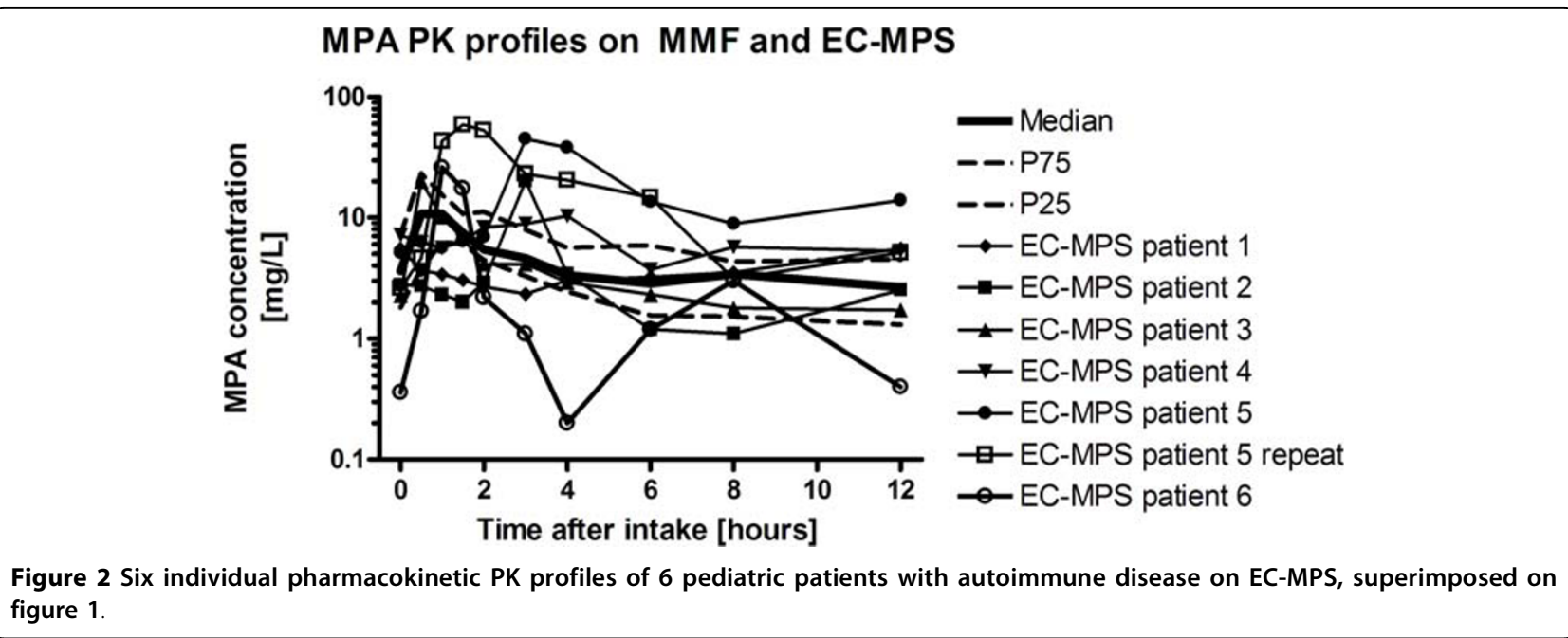

859.2). MPA AUC on EC-MPS had a median of $44.0 \mathrm{mg}$ $\times \mathrm{h} / \mathrm{L}\left(25^{\text {th }}\right.$ percentile $42.0 \mathrm{mg} \times \mathrm{h} / \mathrm{L}, 75^{\text {th }}$ percentile 196 $\mathrm{mg} \times \mathrm{h} / \mathrm{L}$ ), not significantly different from the median AUC from the 22 patients on MMF who had a median AUC of $57.9 \mathrm{mg} \times \mathrm{h} / \mathrm{L}$ (unpaired $\mathrm{t}$-test). The bioequivalent dose for $250 \mathrm{mg}$ of MMF is $180 \mathrm{mg}$ of EC-MPS. The median dose of $724.2 \mathrm{mg} / \mathrm{m}^{2}$ would be equivalent to $1005.8 \mathrm{mg} / \mathrm{m}^{2}$ of MMF which compared to a median of $893 \mathrm{mg} / \mathrm{m}^{2}$ that the 22 patients on EC-MPS were given (not significant). The dose normalized MPA AUC had a median of $0.11 \mathrm{mg} \times \mathrm{m}^{2} \times \mathrm{h} / \mathrm{L} \times \mathrm{mg}\left(25^{\text {th }}\right.$ percentile $0.05,75^{\text {th }}$ percentile $0.25 \mathrm{mg} \times \mathrm{m}^{2} \times \mathrm{h} / \mathrm{L} \times \mathrm{mg}$ ). The dose normalized MPA-AUC in the 22 patients on EC-MPS was $0.057 \mathrm{~m}^{2} \times \mathrm{h} / \mathrm{L}$. After conversion of the of the EC-MPS dose to a bioequivalent dose of MMF, the dose normalized AUC no longer differed from that of the patients on MMF (bioequivalent EC-MPS AUC was $0.14 \mathrm{mg} \times \mathrm{m}^{2} \times \mathrm{h} / \mathrm{L} \times \mathrm{mg}, \mathrm{p}>0.05$, Mann Whitney test). This suggests that in pediatric patients with autoimmune disease the same conversion of the dose with
$250 \mathrm{mg}$ of MMF being equivalent to $180 \mathrm{mg}$ of EC-MPS is applicable.

Patients on EC-MPS showed random PK profiles (figure 2). For the convenience of the reader, we superimposed the actual PK profiles over the percentiles of the MMF profiles.

We then studied whether the trough level could be used to assess the MPA exposure in patients on EC-MPS. Spearman correlation coefficients between AUC and the different $C_{n}$ trough level points revealed no correlation between the trough level. The best correlation was for the 6-hour concentration (Spearman $r=0.919$ ). The median $\mathrm{C}_{6}$ level was $3.21 \mathrm{mg} / \mathrm{L}$, the $25^{\text {th }}$ percentile for the $\mathrm{C}_{6}$ was $1.20 \mathrm{mg} / \mathrm{L}$ and the $75^{\text {th }}$ percentile was $13.5 \mathrm{mg} / \mathrm{L}$. The results of the correlation studies are provided in table 1 . AUC could not be estimated on the basis of the $C_{0}, C_{1}$, $\mathrm{C}_{2}$, or $\mathrm{C}_{4}$ concentrations, which are time points commonly used for limited sampling strategies. Based on the preliminary data from these 6 patients, the 6 -hour concentration should be targeted between $3-4 \mathrm{mg} / \mathrm{L}$.

Table 1 Correlation between exposure (12-hour AUC determined by full 10-point PK profile, calculated using the trapezoid rule) and individual time concentration points.

\begin{tabular}{|c|c|c|c|c|c|c|c|c|c|c|}
\hline Parameter & $C_{0}$ & $C_{0.5}$ & $C_{1}$ & $C_{1.5}$ & $C_{2}$ & $C_{3}$ & $C_{4}$ & $C_{6}$ & $C_{8}$ & $C_{12}$ \\
\hline $\begin{array}{l}\text { Number of } \\
\text { XY Pairs }\end{array}$ & 7 & 7 & 7 & 7 & 7 & 7 & 7 & 7 & 7 & 7 \\
\hline Spearman $r$ & 0.3929 & 0.7500 & 0.2162 & 0.2162 & 0.8571 & 0.7857 & 0.8571 & 0.9190 & 0.6786 & 0.6786 \\
\hline $\begin{array}{l}\text { P value (two- } \\
\text { tailed) }\end{array}$ & 0.3956 & 0.0663 & 0.6615 & 0.6615 & 0.0238 & 0.0480 & 0.0238 & 0.0067 & 0.1095 & 0.1095 \\
\hline $\begin{array}{l}\text { P value } \\
\text { summary }\end{array}$ & ns & ns & ns & ns & * & * & $*$ & $* *$ & ns & ns \\
\hline $\begin{array}{l}\text { Exact or } \\
\text { approximate } \\
\text { P value? }\end{array}$ & Exact & Exact & Exact & Exact & Exact & Exact & Exact & Exact & Exact & Exact \\
\hline
\end{tabular}




\section{Discussion}

The objective of the study was the characterization of the pharmacokinetics of EC-MPS in pediatric patients with autoimmune disease without a concomitant calcineurin inhibitor. As outlined in the introduction, this was necessary as special dosing is required and data from transplant patients cannot simply be applied to these patients. Secondary objectives were to determine whether the recommendations for bioequivalence of dosing can be applied to pediatric patients with autoimmune disease and whether trough level monitoring is feasible to study exposure in these children.

The study demonstrates that bioequivalent dosing of EC-MPS can indeed be implemented using the same conversion (180 mg of EC-MPS for $250 \mathrm{mg}$ of MMF). AUC's achieved with a median dose of $712 \mathrm{mg} / \mathrm{m}^{2}$ resulted in comparable MPA exposure. However, there was substantial inter-individual variability. Furthermore, $t_{\max }$ was random and only the $\mathrm{C}_{6}$ concentration correlated significantly with the exposure.

A bioequivalent dose of $180 \mathrm{mg}$ of EC-MPS being equivalent to $250 \mathrm{mg}$ of MMF has been reported for transplant patients[9]. This has not been shown for pediatric rheumatology patients. This paper provides the first evidence that the same conversion can be applied with comparable AUCs. When correcting for the bioequivalence, the dose-normalized MPA AUCs are also similar. As such, the clinician may switch between both formulations should the gastrointestinal (GI) side effects prevent ongoing use of MMF. However, the jury remains out as to whether conversion to EC-MPS improves the GI side effects [10]. We are unaware of any study in SLE patients that compares GI side effects of both formulations. The GI tolerability of MMF therapy appears less of a problem than in transplant patients, possibly because of the use of concomitant calcineurin inhibitors [11].

Importantly, there was substantial inter-patient variability. There was a wide range of the dose-normalized AUC (maximum 5.6 higher than minimum), confirming data on liver transplant patients that suggest wide interpatient variability [12]. These data stress the need for TDM in pediatric rheumatology patients as has also been shown for adult patients [6]. As with MMF, we recommend that at least one full PK profile be obtained on stable dosing in these patients [3]. Unfortunately, trough level monitoring, which forms the mostly widely used TDM strategy, is not feasible in these patients. There is absolutely no correlation at all between AUC and $C_{0}$ or $C_{12}$. It is well established that trough level monitoring of MPA is insufficient in transplant recipients [13]. Limited sampling strategies are used instead, most commonly involving $C_{0}, C_{1}, C_{2}$ and $C_{4}$ [14]. Based on the preliminary results in this study, these strategies will fail. Only the $\mathrm{C}_{6}$ concentration correlates significantly with the trough level. Our study provides insufficient numbers to establish a limited sampling model based on the $\mathrm{C}_{6}$ concentration. The authors encourage multi-center studies on pediatric rheumatology patients on EC-MPS to establish such strategies. Until these become available, a full PK profile should be entertained to determine that patients have adequate exposure.

The question about what exactly comprises adequate exposure remains to be determined. Recent evidence from transplant studies suggests that an AUC greater than $30 \mathrm{mg} \times \mathrm{h} / \mathrm{L}$ is required to prevent rejection [15]. However, no upper therapeutic window could be established. Generally, SLE patients are aimed at a higher AUC [6], and the therapeutic window has not yet been formally confirmed in randomized controlled clinical trials. It appears that the EC-MPS dose of $712 \mathrm{mg} / \mathrm{m}^{2}$ may provide adequate exposure with a target AUC of 60 $\mathrm{mg} \times \mathrm{h} / \mathrm{L}$. None of the patients relapsed on the respective doses with their measured AUCs, but the follow-up is short (367 days, range 106-612 days, data not shown in results) and the numbers are insufficient to draw any conclusions.

Our study is limited by the small number of patients studied. Nonetheless, the observation of the random $t_{\max }$ and the very substantial inter-patient variability clearly warrants the need for TDM in these patients. The limited sampling strategies typically employed for MMF therapy are inadequate, thus further studies are needed to assess the feasibility of the 6-hour concentration. The authors stress the need for TDM in these patients using full PK profiles.

\section{Conclusion}

A full pharmacokinetic profile is required to assess the MPA exposure when treating patients with EC-MPS. The 6-hour concentration can provide a rough estimate of this exposure. Based on the preliminary data from only 6 patients, the 6 -hour concentration should be targeted between $3-4 \mathrm{mg} / \mathrm{L}$.

\section{Abbreviations \\ AUC: Area under the curve; $C 0$ : pre-dose trough level; $C_{\text {max }}$ maximum concentration; $\mathrm{C}[\mathrm{n}]$ : level drawn at $[\mathrm{n}]$ hours after oral intake - example; $\mathrm{C2}$ : concentrations at 2 hours; EC-MPS: Enteric coated mycophenolate sodium; EMIT: enzyme-mediated immunoassay technique; IMPDH: Inosine Monophosphate Dehydrogenase; MMF: Mycophenolate mofetil; MPA: Mycophenolic acid; r: Spearman rank r; SLE: systemic lupus erythematosus; $t_{\text {max }}$ : time to maximum concentration after oral intake; TDM: Therapeutic drug monitoring.}

\section{Acknowledgements}

The authors wish to thank Mrs. Shelley Casier, Advanced Practice Nurse, for the coordination of the testing and the data collection. 


\section{Authors' contributions}

GF designed the study, collated the data, performed the analysis, and drafted the manuscript. AY performed the statistical analysis and helped to draft the manuscript. DL in the design of the study and carefully edited the manuscript. AS participated in the design of the study and coordination and helped to draft the manuscript. All authors read and approved the final manuscript.

\section{Competing interests}

The authors declare that they have no competing interests.

Received: 1 October 2009

Accepted: 4 January 2010 Published: 4 January 2010

\section{References}

1. Allison AC: Mechanisms of action of mycophenolate mofetil. Lupus 2005, 14(Suppl 1):s2-8.

2. Appel GB, Contreras G, Dooley MA, Ginzler EM, Isenberg D, Jayne D, Li LS, Mysler E, Sánchez-Guerrero J, Solomons N, Wofsy D, Aspreva Lupus Management Study Group: Mycophenolate mofetil versus cyclophosphamide for induction treatment of lupus nephritis. J Am Soc Nephrol 2009, 20:1103-12

3. Filler G, Hansen M, LeBlanc C, Lepage N, Franke D, Mai I, Feber J: Pharmacokinetics of mycophenolate mofetil for autoimmune disease in children. Pediatr Nephrol 2003, 18:445-9.

4. Filler G, Zimmering M, Mai I: Pharmacokinetics of mycophenolate mofetil are influenced by concomitant immunosuppression. Pediatr Nephrol 2000, 14:100-4.

5. Zahr N, Amoura Z, Debord J, Hulot JS, Saint-Marcoux F, Marquet P, Piette JC, Lechat P: Pharmacokinetic study of mycophenolate mofetil in patients with systemic lupus erythematosus and design of Bayesian estimator using limited sampling strategies. Clin Pharmacokinet 2008, 47:277-84.

6. Roland M, Barbet C, Paintaud G, Magdelaine-Beuzelin C, Diot E, Halimi JM, Lebranchu Y, Nivet $\mathrm{H}$, Büchler M: Mycophenolate mofetil in patients with systemic lupus erythematosus: a prospective pharmacokinetic study. Lupus 2009, 18:441-7.

7. Filler G, Buffo I: Safety considerations with mycophenolate sodium. Expert Opin Drug Saf 2007, 6:445-9, Review..

8. Schutz E, Shipkova M, Armstrong WW, Niedmann PD, Weber L, Tonshoff B, Pethig K, Wahlers T, Braun F, Ringe B, Oellerich M: Therapeutic drug monitoring of mycophenolic acid: comparison of HPLC and immunoassay reveals new MPA metabolites. Transplant Proc 1998, 30:1185-7.

9. Johnston A, He X, Holt DW: Bioequivalence of enteric-coated mycophenolate sodium and mycophenolate mofetil: a meta-analysis of three studies in stable renal transplant recipients. Transplantation 2006, 82:1413-8.

10. Darji P, Vijayaraghavan R, Thiagarajan CM, Sharma RK, Subbarao B, Pishardy R, Dakshinamurthy KV, Vijaykumar R, Abraham G, Bhaskar S, Agarwal L, Shah B, Abraham A, John M, Sampathkumar K, Das T, Umesh L, Sundar S, Ballal H, Jasuja S, Saxena S, Saha TK: Conversion from mycophenolate mofetil to enteric-coated mycophenolate sodium in renal transplant recipients with gastrointestinal tract disorders. Transplant Proc 2008, 40:2262-7.

11. Traitanon O, Avihingsanon $Y$, Kittikovit V, Townamchai N, Kanjanabuch T, Praditpornsilpa K, Wongchinasri J, Tungsanga K, Eiam-Ong S: Efficacy of enteric-coated mycophenolate sodium in patients with resistant-type lupus nephritis: a prospective study. Lupus 2008, 17:744-51.

12. Perry TW, Christians U, Trotter JF, Bendrick-Peart J: Pharmacokinetics of enteric-coated mycophenolate sodium in stable liver transplant recipients. Clin Transplant 2007, 21:413-6.

13. Gajarski RJ, Crowley DC, Zamberlan MC, Lake KD: Lack of correlation between MMF dose and MPA level in pediatric and young adult cardiac transplant patients: does the MPA level matter?. Am J Transplant 2004, 4:1495-500.

14. Filler G: Abbreviated mycophenolic acid AUC from C0, C1, C2, and C4 is preferable in children after renal transplantation on mycophenolate mofetil and tacrolimus therapy. Transpl Int 2004, 17:120-5.

15. Le Meur Y, Büchler M, Thierry A, Caillard S, Villemain F, Lavaud S, Etienne I, Westeel PF, Hurault de Ligny B, Rostaing L, Thervet E, Szelag JC, Rérolle JP,
Rousseau A, Touchard G, Marquet P: Individualized mycophenolate mofetil dosing based on drug exposure significantly improves patient outcomes after renal transplantation. Am J Transplant 2007, 7:2496-503.

doi:10.1186/1546-0096-8-1

Cite this article as: Filler et al:: Random pharmacokinetic profiles of ECMPS in children with autoimmune disease. Pediatric Rheumatology 2010 8:1.
Publish with Bio Med Central and every scientist can read your work free of charge

"BioMed Central will be the most significant development for disseminating the results of biomedical research in our lifetime. "

Sir Paul Nurse, Cancer Research UK

Your research papers will be:

- available free of charge to the entire biomedical community

- peer reviewed and published immediately upon acceptance

- cited in PubMed and archived on PubMed Central

- yours - you keep the copyright
BioMedcentral 